\title{
Osman Hamdi Bey'in Resimlerinde Geleneksel İzler
}

\author{
Arzu TÜYBEK
}

Yüksek Lisans Öğrencisi, Necmettin Erbakan Üniversitesi, Güzel Sanatlar ve Mimarlık Fakültesi, Geleneksel Türk Sanatları Bölümü, Konya, Türkiye, arzumath42@gmail.com

\author{
Ali Fuat BAYSAL
}

Doç. Dr., Necmettin Erbakan Üniversitesi, Güzel Sanatlar ve Mimarlık Fakültesi, Geleneksel Türk Sanatları Bölümü, Konya, Türkiye, afbaysal@gmail.com

Ayşe Zehra SAYIN iD

Öğr. Gör. Dr., Necmettin Erbakan Üniversitesi, Güzel Sanatlar ve Mimarlık Fakültesi, Geleneksel Türk Sanatları Bölümü, Konya, Türkiye, aysezehrasayin@gmail.com

\begin{tabular}{|c|c|}
\hline Makale Bilgileri & ÖZ \\
\hline $\begin{array}{l}\text { Makale Geçmişi } \\
\text { Geliş: } 20.10 .2021 \\
\text { Kabul: } 15.12 .2021 \\
\text { Yayın: } 21.12 .2021 \\
\text { Anahtar } \\
\text { Kelimeler: } \\
\text { Resim, } \\
\text { Geleneksel, } \\
\text { Motif, } \\
\text { Osman Hamdi Bey. }\end{array}$ & $\begin{array}{l}\text { Geleneksel Türk sanatlarımızın gelecek nesillere aktarımında farklı sanat dallarından ve sanatın farklı ifade } \\
\text { biçimlerinden faydalanılmış̧ır. Türk resim sanatının bu bağlamda önemli bir misyon üstlendiği söylenebilir. } \\
\text { Türk resim sanatının önemli temsilcileri arasında yer alan Osman Hamdi Bey’in eserleri, geleneksel Türk } \\
\text { sanatlarına ait özellikleri yansıtması bakımından önem teşkil etmektedir. Bu araştırmada Osman Hamdi } \\
\text { Bey’in eserleri, geleneksel Türk sanatlarının motif, renk ve kompozisyon özellikleri bakı mından } \\
\text { incelenmiş ve değerlendirilmiştir. Araştırma kapsamında Osman Hamdi Bey'e ait olup } \\
\text { günümüzde çeşitli müzlerde sergilenen, "İki Müzisyen Kız, "Kur'an Okuyan Adam”, "Yeşil } \\
\text { Türbe'de Dua" ve "Halı Satıcısı" isimli dört eser, örneklem olarak seçilmiştir. Yapılan } \\
\text { incelemeler ve betimlemeler sonucunda araştırma kapsamında incelenen eserlerde, millî, kültürel } \\
\text { ve inanca dayanan anlatım biçimlerinin sembollerle işlendiği görülmektedir. Özellikle iç mekân } \\
\text { betimlemelerinde, esere konu olan yapının duvar ve halılarında yer alan motif, kompozisyon ve } \\
\text { renk örneklerinin, oldukça gerçekçi ve canlı resmedildiği dikkat çekmektedir. Dolayısıla } \\
\text { sanatçının tablolarında kullandığı nesne ve mekânların üzerinde bulunan geleneksel motif ve } \\
\text { desenlerin, orjinallerine bağlı kalarak yansıtıldığı tespit edilmiştir }\end{array}$ \\
\hline
\end{tabular}

\section{Traditional Traces in Osman Hamdi Bey's Paintings}

\begin{tabular}{|c|c|}
\hline Article Info & ABSTRACT \\
\hline Article History & \\
\hline Received: 20.10 .2021 & generation. It can be said that Turkish painting art has an important role. Osman Hamdi's painting \\
\hline Accepted: 15.12 .2021 & who was the important artist of Turkish paintings art reflects the features of Turkish painting. In \\
\hline Published: 21.12 .2021 & this study Osman Hamdi's painting has been viewed on Traditional Turkish Art parts such \\
\hline Keywords: & $\begin{array}{l}\text { as designs, motives, colors and compositions. Four painting that exhibits in different galleries, "İki } \\
\text { Müzisyen Kız" "Kur'an Okuyan Adam", "Yeșil Türbe'de Dua" and "Halı Satıcısı" are chozen as }\end{array}$ \\
\hline Picture, & sample. It's seen that national, cultural and relegionals expressions pictured by symbols. Especially \\
\hline Traditional, & in door picture are important on reality and vivid reflections by using motives, compositions and \\
\hline $\begin{array}{l}\text { Motifs, } \\
\text { Osman Hamdi Bey. }\end{array}$ & $\begin{array}{l}\text { color sample of walls and carpets. As a result, it is understood that the artist reflected the traditional } \\
\text { motives and figures as the same with real life of objects and places. }\end{array}$ \\
\hline
\end{tabular}

Atıf/Citation: Tüybek A. Baysal A. F. Sayın A. Z. (2021). Osman Hamdi Bey’in Resimlerinde Geleneksel İzler, Konya Sanat Dergisi, 4, 52-65.

"This article is licensed under a Creative Commons Attribution-NonCommercial 4.0 International License (CC BY-NC $4.0) "$ 


\section{GíRiş}

Sanat, geçmişten günümüze kadar her alanda değişim geçirmiş, gelişmiş, süreç içerisinde kendini yenilemiş ve hâlen de yenilemeye devam etmektedir.

Sanat kavramı elbette hiçbir milletin tekelinde değildir. Ancak milletler bir sanata damgalarını vurdukları oranda onun kendi öz benlikleriyle ilgili olduğunu başka milletlere kabul ettirebilir ve bunu savunabilirler. Yoksa bu çabaları taklit olarak kalmaya mahkûm olacaktır (Derman, 2001).

Ulaşılan kaynaklar göz önüne alındığında Türk resim sanatının tarihsel süreci, VIII. yüzyıldan itibaren başlamakta ve bin yıldan fazla bir zamana yayılmaktadır. Aslanapa, eski Türk resminin asıl temsilcilerinin, sanata çok yatkın olan Uygur Türkleri olduğundan ve Eski Uygur şehirleri harabelerinde bulunan minyatürler ve duvar resimlerinin Türk resminin bugüne kadar tespit edilen en eski örnekleri olduğundan bahsetmektedir (Aslanapa, 1989).

Geleneksel Türk sanatları denildiğinde, bu sanatlara giren birçok çalışma alanı olmakla beraber, teknikler tamamen farklı olsa da ortak motifler mevcuttur. Bu ortak motifler, Türk toplumunun zaman içinde bir kültür oluşturmasına, Türk süsleme sanatlarında bir üslubun gelişmesine yol açmıştır. Bu üsluba geleneksel Türk sanatları denilmektedir. Resimlerinde ele aldığı konular itibarıyla geleneksel Türk sanatlarına sahip çıkan Osman Hamdi Bey’in araştırma kapsamında ele alınan dört eseri, bu çalışmanın ana muhtevasını oluşturmaktadır.

\section{Geleneksel Sanatların Türk Resim Sanatına Etkisi}

Sanat ve kültür alanında geleneksel olarak ifade edilen biçimlerin modern sanatta doğru uygulanabilmesi, tarihî gelişimlerinin de göz önüne alınarak irdelenmesiyle mümkün olabilmektedir. Sanatsal gelişmelerin bu bağlamda tarihsel olay ve dönemler çerçevesinde değerlendirilmesi gerekmektedir.

Gelenek algısı bazı çevrelere göre muhafazakâr ve kutsal olanı destekleyen bir algılamaya mahkûmdur ve bu anlamda önyargılara maruz kalan bir kavramdır. Geleneksel kavramının geçmişten günümüze gelen bir süreç olması kaçınılmazken bizde gelenek ve modernin birbirine etkisini belirleyen temel etken Doğu-Batı ayrışmasıdır. Modern tabiri daima Batı'yı geleneksel tabiri ise her zaman Doğu'yu temsil ederek birini mistik ve dinsel, diğerini materyal ve seküler olanla ilişkilendirip bu kavramları böyle kabul etmek bazı ön yargılardan kaynaklanmaktadır. Oysa gelenek, geçmişte kalmış, tarihteki sürecini tamamlamış tabiri caizse modası geçmiş bir kavram değil, günümüzü ileriye, geleceğe aktaracak büyük ve köklü bir sürecin adıdır (İlden, 2013).

Tarih boyunca tezhip, minyatür, çini gibi geleneksel sanat alanlarından her biri resim, seramik, grafik, heykel gibi her unsurun kendi disiplin adı ile anılması çabasında olmamıştır. Oysa resim, heykel ya da plastik sanatların herhangi bir dalında çalışan bireylerin kullandıkları malzeme ve seçtikleri konu gibi pek çok unsur geleneksel tabir edilen ögelerden oluşmasına rağmen bunlar geleneksel resim, geleneksel heykel veya geleneksel seramik gibi adlandırılmaz ya da yorumlanmaz. Çoğunlukla, geleneksel adı altında farklı özelliklere sahip olan sanat dalları bir bütün olarak düşünülürken, aynı zamanda sanatın diğer alanlarından kendilerini ayrıştırma yoluna gidilmektedir.

Geçmişimizden bize miras olan ve yeni nesillere aktarmada önemli roller üstlendiğimiz geleneksel ve modern sanatların var olma sürecinden başlanarak sınıflandırmayla ilişkilendirilip ötelemek yerine sanat algısı ve eğitiminin tekrar gözden geçirilmesi gerekmektedir. Böylelikle ne oldukları, niçin ve nasıl yapıldıkları hususunda Türk sanatlarının gerekli hassasiyetle tanıtılması sağlanmış olacaktır (İlden, 2013). 


\subsection{Türk Resim Sanatı}

Türklerin bilinen dört bin yıllık tarihi boyunca, değişik coğrafyalarda devlet kurarak buralarda yaşamaları daima dünyanın ilgisini çekmiştir. Arap, Çin, Hint, Fars ve elbette Batı kültürü ile karşılaştıkları ve iç içe yaşadıkları hâlde Türklerin, öz benliklerini ve kültürlerini sağlam bir şekilde devam ettirmeleri hep merak konusu olmuştur. İslam Dünyasının hâkimi olan ve DoğuBatı ticareti ile dikkat çeken Türklerin ulaştıkları medeniyetin Batı üzerindeki etkisi, Batı' daki doğu bilimci ve seyyahların eserlerine de konu olmuştur. Türk süsleme sanat,, Türk minyatürleri, hat sanat1, damga örnekleri, kilim ve halı sanatı, dünya sanat tarihinin temel yapı taşlarındandır (Bayramoğlu, 2013).

Geleneksel sanatların hat, tezhip, çini, minyatür, halı-kilim vb. alanlarında eserler üreten sanatçılar bir yandan geçmişin izlerini taşıyan formları kendi üsluplarıyla yeniden icra ederken diğer yandan yaşadıkları zamanın da etkisiyle özgün tasarımlar ortaya çıkarmaya uğraş vermektedir (İlden, 2013).

Eski Türk resim sanatı VIII. yüzyıldan günümüze kadar üç din çerçevesinde şekillenerek Budizm, Maniheizm ve İslamiyet Devri olmak üzere üç ana bölümle bin yılı aşkın bir süreci kaplamıştır. Eski Türk resminin ana temsilcileri, sanata çok ilgili ve yetenekli olan Uygur Türkleridir. Uygur şehirleri harabelerinde bulunan, rahiplerin, müzisyenlerin tasvir edildiği, kırmızı ve koyu mavinin çok olduğu parlak renklerin kullanıldığı minyatürler ve duvar resimleri, Türk resminin bugüne değin bilinen en eski örnekleridir. Portre yapmak, yani insan yüzüne karakteristik özelliğini yansıtmak sanatı da ilk defa 750'den sonraki Türk duvar resimlerinde görülmüştür. Bu yıllara kadar insan yüzleri de, vücutlarının diğer kısımları gibi şemalarla çiziliyor ve resmin altına kişinin ismi yazılarak ayırt edilebiliyordu (Aslanapa, 2000). Her ne kadar bazı tutucu çevreler, müzik, resim ve heykel yapılmasını yanlış yorumlarla kısmen engellemeye çalışsa da hükümdarlar başarılarını sanattan da faydalanarak sergilemişlerdir. Örneğin Fatih Sultan Mehmet, İtalya'dan Bellini'yi getirterek portresini yaptırmıştır. Osmanlılarda batılı anlamda 1870'lerden sonra resim yapılmaya başlanmıştır. Osmanlı Dönemi'nde mimari sanatının gelişmesinde Türk zevkinin etkisi büyüktür. Selçuklular Dönemi'nde Türkler, yapı ve süsleme sanatına Beylikler devrinde de süren bazı yenilikler getirmiş̧lerdir. Mekân anlayışının gelişmesi, camilerde son cemaat yerinin doğması, doluluk ve boşlukların dengelenmesi, avlunun cami gövdesine katılması, mermer kaplamanın kullanılması gibi. Osmanlı Dönemi’nde mekân anlayışı daha da gelişerek Mimar Sinan'ın eserleriyle olgunluğuna erişmiştir (Çubukçu, 1987).

16. yüzyıl, Osmanlı Devleti’nin siyasal ve ekonomik gelişmelerin oldukça yüksek olduğu, yazma eserlerin, minyatürlerin, tezhip ve çini gibi sanatların verimlilikte zirvelere ulaştığı bir dönemdir. Osmanlılar, güzelliği abartılı süste değil, çizgi ve biçimlerin sadeliği ve uyumunda aramışlardır.

\section{Osman Hamdi Bey ve Sanatçı Kişiliği}

Osman Hamdi Bey, 30 Aralık 1842'de İstanbul'da doğmuş olup, Sadrazam İbrâhim Edhem Paşa'nın oğlu, İsmâil Galib ve Halil Edhem (Eldem)'in ağabeyidir. Ailesinin büyük katkısıyla çok yönlü bir kişi olarak yetişmiştir. Hukuk tahsili için 1857'de Paris'e giden sanatçı, bir taraftan hukuk alanında öğrenimine devam ederken bir taraftan da arkeolojiyle ilgilerek, Paris Güzel Sanatlar Yüksek Okulunda resim eğitimi aldı. Sanata ve özellikle de resme olan alakası hukuktan çok daha ağır basınca, zamanın ünlü ressamları olan Boulanger ve Jean-Leon Gérôme'nin atölyelerinde çalıştı. Osman Hamdi Bey, yurda döndükten sonra 1881'de Müze-i Hümâyunun müdürlüğüne getirilmesi sonrasında kültür ve sanat alanındaki çalışmaları yoğunlaşırken Türk müzeciliğinde yepyeni bir dönem başladı. Otuz yıllık Müze-i Hümâyun, Osman Hamdi'nin çabalarıyla İstanbul 
Arkeoloji Müzelerine dönüştürüldü (Gündüz, 2007).

Tablolarında daha çok fotoğraflardan yararlanarak birleştirmeci üslûpta eserler veren sanatçının kompozisyonlarında, saydam bir ş̧ık, net ve anlaşılır bir çevre düzeni, titiz bir biçimde boya kullanımı dikkat çekmektedir. Sanatçı, eserlerine formu verebilmek için 1 ş1k ve gölgeden faydalanırken, eşyanın kendi rengine sadık kalmıştır. Osman Hamdi Bey; müzeci, ressam, arkeolog ve yazar kimliklerinin yanısıra bürokrasideki başarısı, bilim adamlığı ile de anılarak, ömrünün sonuna kadar takdire şayan çalışmalar sergilemiştir. Yurt içi ve yurt dişındaki müzelerde ve pek çok koleksiyonda eserleri bulunan Osman Hamdi Bey'in "Camiden Çıkış", "Halı Satıcısı", "Yeşilcami'de Kur'an Okuma”, "Kaplumbağa Terbiyecisi”, "Âbıhayat Çeşmesi”, "Şehzade Türbesinde Derviş ve Türbe Kapısı Önünde Kadınlar" en önemli eserlerindendir (Gündüz, 2007).

\subsection{Osman Hamdi Beyin Eserlerinde Geleneksel İzler}

Sultan Abdülaziz döneminde (1861-1876), resim sanatına olan ilgi ve destek fazlasıyla artmış, sanatçıların eğitimi için gerekli imkânlar verilmiş, saray ressamlığı kurumu oluşturularak, saray için eserler toplanmaya başlanmıştır. Türkiye'nin batılı anlamda ilk tablo koleksiyonu, Dolmabahçe Sarayında oluşturulmuştur. Bu anlamda resim, son dönem Osmanlı sarayının kültür ve sanat hayatının ayrılmaz parçası olarak yer almıştır. 32. Osmanlı padişahı olarak tahta çıkan ve güçlü bir hattat, başarılı bir besteci olan Sultan Abdülaziz, resme olan ilgi ve yeteneği ile sultansanatçı kimliğinde yeni bir dönem başlatmıştır. Mısır ve Avrupa gezileri sırasında ziyaret ettiği saray ve müzelerde edindiği izlenimlerin de etkisiyle, pek çok Türk ressamının yetişmesinde ve resim sanatımıza kazandırılmasında önemli rol oynayan sultan Abdülaziz; sanat koruyucusu kimliği yanında, ressam kimliği ile de adını duyurmuş, Türk plastik sanatları açısından cesur adımlar atmıştır. Batılı anlamda Türk resminin ilk kuşağını yaklaşık 1850-1860 yılları arasında etkin olan asker ressamlar oluşturmuştur. 1870-1880'li yıllarda etkin olan ikinci kuşak ise Osman Hamdi Bey, Osman Nuri Paşa, Şeker Ahmed Paşa ve Süleyman Seyyid Bey gibi asker ve sivil ressamlar tarafindan temsil edilmektedir (Kaya, 2019).

Çok yönlü bir kişiliğe sahip olan Osman Hamdi Bey'in üzerinde dikkatle durulmas1 gereken belki de en önemli yönü ressamlığıdır. Babası tarafından Paris'e hukuk öğrenimine gönderilmiş olmasına rağmen güzel sanatlara olan ilgi ve sevgisi, hukuku geri plana atarak sanat yolunu seçmesi, belki de hayatı boyunca mutluluğu nerede arayacağının bir işaretiydi. Hamdi beyin çalışma hayatında müzeciliğe dört elle sarılmasını, arkeolojik kazılara şevkle koşturmasını sanayi i nefise mektebini kurmasını sağlayan güzel sanatlar sevgisinin itici gücüydü. Bu sevgi ve itici güç Ressam Osman Hamdi'yi Türk toplumuna hediye etmiş oldu (Cezar, 1971).

Paris’te kompozisyon, renk, 1şık, valör, ton eğitim görmüş figüratif resmin gelişiminde önemli bir yeri olan Osman Hamdi Bey, aile bireylerinin portrelerini ve bazı manzaraları natüralist bir yaklaşımla betimlemiştir. Yetiştiği toplumun tarihsel zenginliğini ve geleneklerini yansıttığı oryantalist konulu tablolarının, yabancı ressamların yaptı̆̆ 1 oryantalist eserlerden farklı olduğu dikkate değer bir olgudur. Bağdat'ta Vilayet-i Umur-u Ecnebiye Müdürlüğü görevinde bulunmuş ve bu esnada kentin çeşitli görünümlerini yansıtan tablolar yapmış, geleneksel ögeleri resimlerinde göstermiştir. 1871'de sarayda Teşrîfat-1 Hariciye müdür muavini olmuş, günümüz tabiriyle sergi küratörlügünü yaptığı Evrensel 1873 Viyana Sergisi'nde sergilediği kendi eserleriyle Osmanlı İmparatorluğu'na altın madalya kazandırmıştır (Kaya, 2019).

Osman Hamdi, tablolarında Doğu'da yetişmiş biri olarak, batılı ressamlardan farklı bir yaklaşımla, kendi toplumunu yansıtmıştır. Sanatçı, çalışmalarındaki modellerin büyük bir kısmında kendisi, ailesi ve çevresindeki kişilerin fotoğraflarını kullanmıştır. Bu yüzden Türk resim sanatındaki ilk portre ressamı olarak da anılır. 
Osman Hamdi Bey, resimlerinde dekorasyon unsuru olarak genellikle tarihî yapıları, Osmanlı mimari eserleri ve bu eserlerdeki bezemeleri ve detayları büyük bir titizlikle kullanmıştır. Bu mimari eserlerin iç ve dış görünümlerinin yanı sıra aksesuar olarak tarihî eşyalara da yer vermiş, camii ve türbelerin içerisinde bulunan rahleleri, kitapları, şamdanları, mumları, kandilleri, halıları ve hat levhaları ayrıntılı bir şekilde tuvallerine işlemiştir. Osman Hamdi Bey bazı resimlerinde daha fazla halı kullanmış ve bu halıların üzerindeki desenleri, motifleri ve renkleri gerçeğe uygun bir şekilde tasvir etmiştir. Bunun yanı sıra halıları kullanım amaçlarına uygun olarak bir kompozisyon içerisinde yansıtmıştır. Örneğin, bir halı seccade, namaz kılan bir figürle birlikte tasvir edilmiştir (Bayraktaroğlu, 2011). Bu araştırmada Osman Hamdi Bey’e ait olup günümüzde çeşitli müzlerde sergilenen, “İki Müzisyen Kız, “Kur'an Okuyan Adam”, "Yeşil Türbe’de Dua” ve "Halı Satıcısı" isimli dört eser içerisinde barındırığı geleneksel motifler bazında betimlenecek ve değerlendirilecektir.

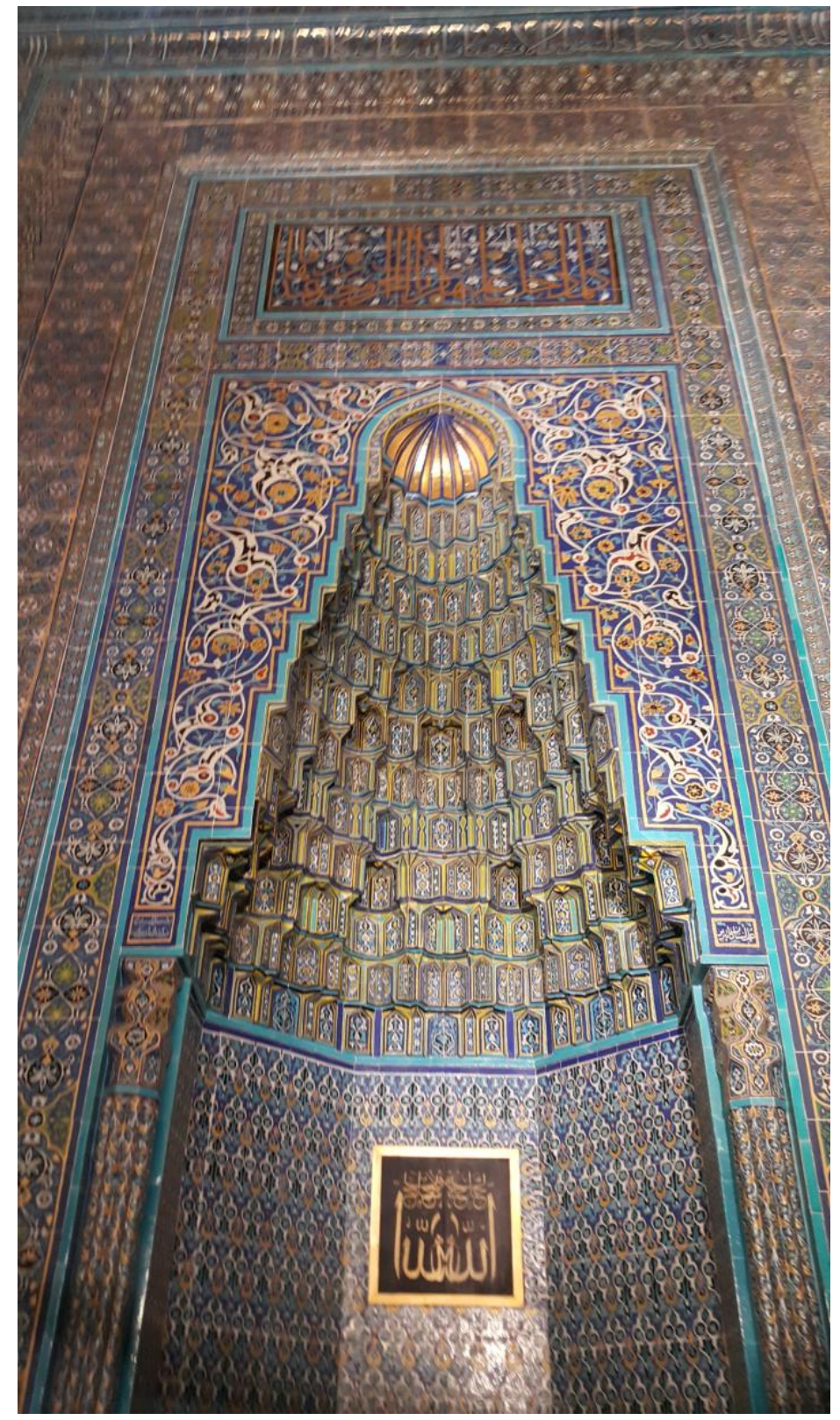

Fotoğraf 1. Yeşil Cami Mihrabı (URL-1)

Tezyini motifleri ve Anadolu halk nakıslarını ve mimari yapıların süslemelerini resimlerine yansıtan Osman Hamdi Bey'in resimlerinde en sık kullandığı mimari yapı olan Bursa Yeşil Cami 
erken Osmanlı çini sanatının en zengin örneklerini barındırır. Tek renkli altıgen formlu ve firuze renkli üçgen formlu çinileri günümüze kadar ulaşabilmiştir. 10 metreyi aşan yüksekliği ile mihrap (Fotoğraf 1), Anadolu'nun en önemli çini mozaik bezemelerindendir. Kufi ve nesih harflerden oluşan yazı şeridi, mukarnaslar, kabartmalı geometrik bezemeler mihrap nişini çevreler. Mihrap çinilerinde bitkisel motifler, rumiler, hatailer ve geometrik desenler; lacivert zemin üzerine sarı, firuze, yeşil renklerle kullanılmıştır. Çini bezemelerin etkili olduğu sultan locası çinilerinde mavi, yeşil ve sarı renkler daha koyudur (Maltepe, 2019).

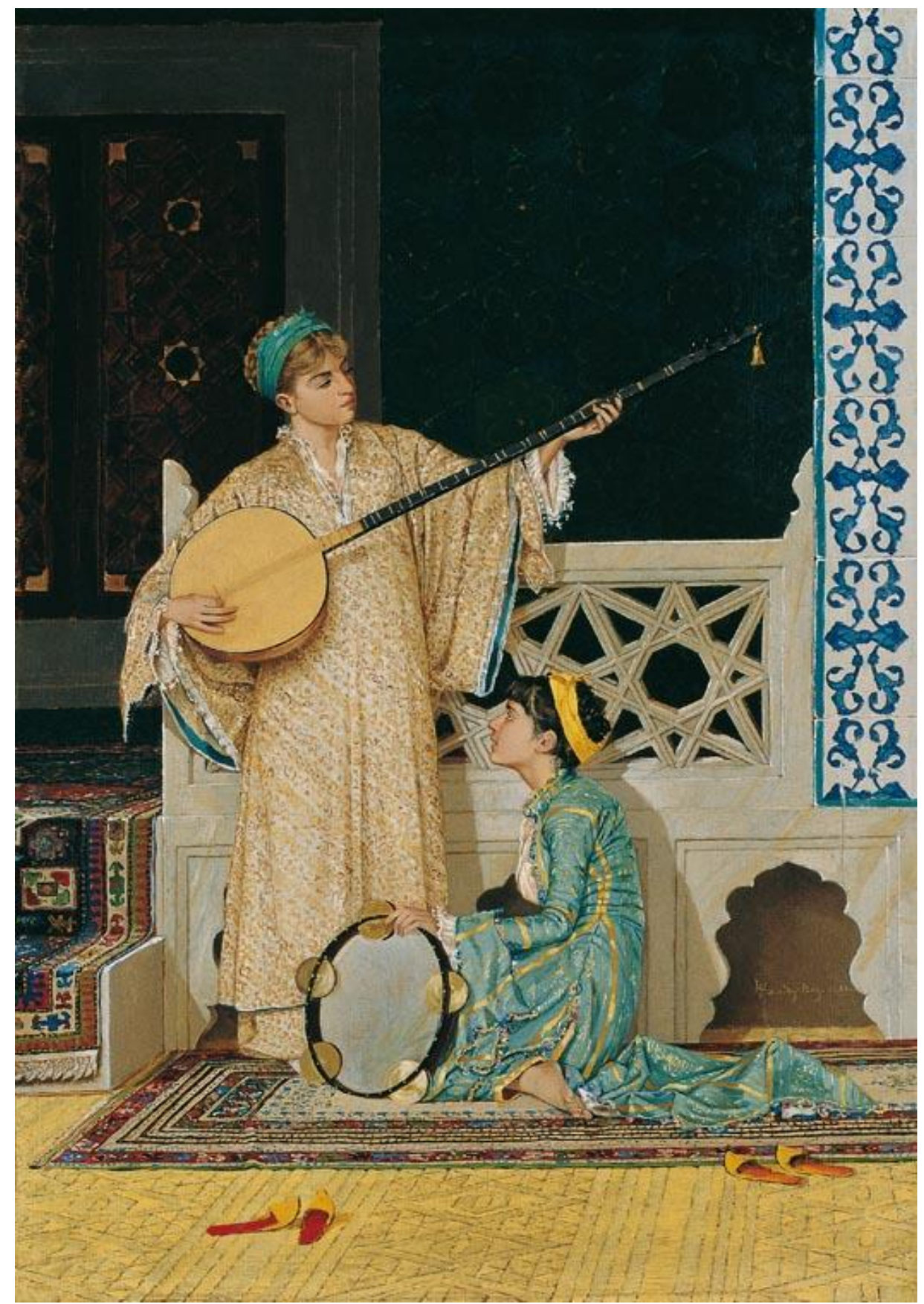

Şekil 1. İki Müzisyen Kız. Yapım Yıll: 1880. Tekniği: Tuval üzerine yağlı boya. Boyut: $58 \mathrm{~cm} \times 39 \mathrm{~cm}$. Bulunduğu Yer: İstanbul Beyoğlu Pera Müzesi(URL-2)

İki Müzisyen Kız isimli eser (Şekil 1) Osman Hamdi Bey’in en önemli eserlerinden biri olup, Bursa Yeşil Camii'deki namazgâh bölümü tabloda yer alan mekândır. Bu bölümün giriş kısmında geleneksel çalgılarımızdan def ve tambur çalan iki genç kız durmaktadır. Def çalan kız 
otururken, tambur çalan kız ayakta durmaktadır. Ayakta duran kız saçlarına mavi bir yemeni bağlamış, üzerinde ise krem rengi zemine altın sarısı desenler olan bir elbise ve aynı kumaştan bir şalvar vardır. Oturan kız altın sarısı renginde bir yemeni bağlamış, üzerinde ise mavi üzerine altın sarısı renginde şeritler olan bir üç etek vardır (Harmankaya, 2015).

Söz konusu tablo, caminin namazgâh bölümünde (Fotoğraf 2) iki farklı geleneksel Türk müzik aletinin sazını çalan genç, iki farklı pozisyondaki kızla yetenekli Osmanlı kadınını temsil ediyor. Osman Hamdi Bey'in yapıtlarının genel bir üslubu olarak Batılılaşma dönemin de çeşitli yeteneklere ve güçlü kişisel kimliklere sahip kadın figürleri önemli rol oynamıştır. Bu yüzden bu resim dahil yapıtlarında enstrüman çalan, kitap okuyan kadınlara rastlıyoruz. Aynı zamanda Osman Hamdi Bey'in resimlerinde diğer batılı oryantalistlerin aksine cinselliğe vurgu yapılmamaktadır. Yani bu çalışmadan da görebileceğimiz gibi kadınların, dönemin giyiniş tarzlarına uygun olarak kapalı giyindikleri göze çarpmaktadır. Bu eserin en önemli özelliklerinden biri de Hamdi Bey'in Osmanlı kültürüne ait süsleme eşyalarına yaklaşımıdır. Halı, oyma ahşap işçiliği, çini, taş oymacılığ1 ve def gibi unsurlar eserlerinde sık rastlanır. Üstelik hocası Jean-Léon Gérome'dan etkilenen Osman Hamdi Bey, dönemin geleneksel temalarını esimlerinde konu olarak tasvir etmeyi tercih eden hatta bazı eserlerinde belge niteliği taşıyan detaylara yer veren bir sanatçıdır (Yerli, 2020).

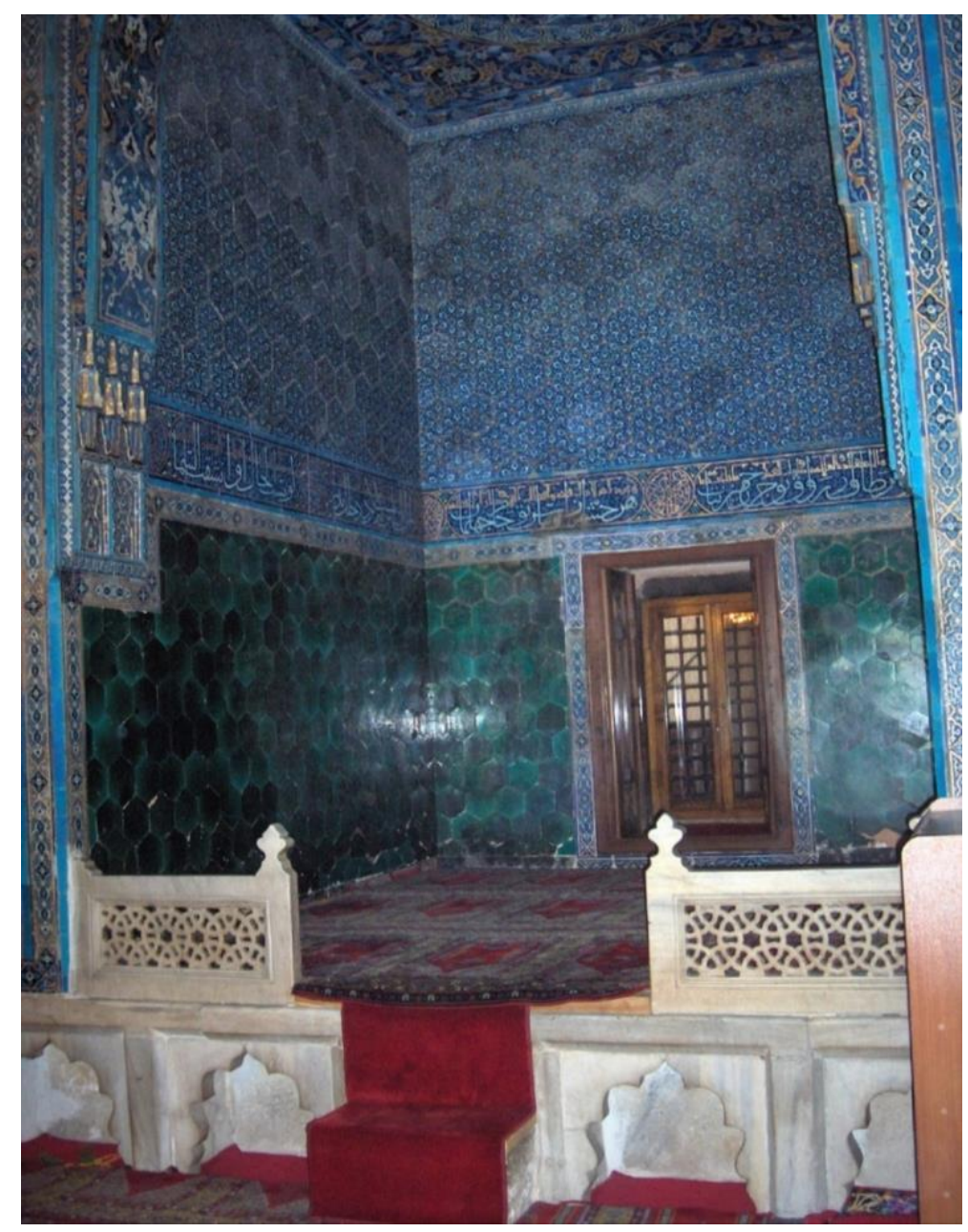

Fotoğraf 2. Yeşil Camiinin Namazgâh Bölümü (URL-3)

1880 yılında yaptığ “íki Müzisyen Kız" tablosunda kullandığg mekânı bu kez Osman Hamdi Bey başka bir tablosunda gerçek mekânla, yani Bursa Yeşil Camii'den bir bölümü, bu defa daha uyumlu olarak "Bursa Yeşil Camii’ de” tablosunda kullanmıştır. 


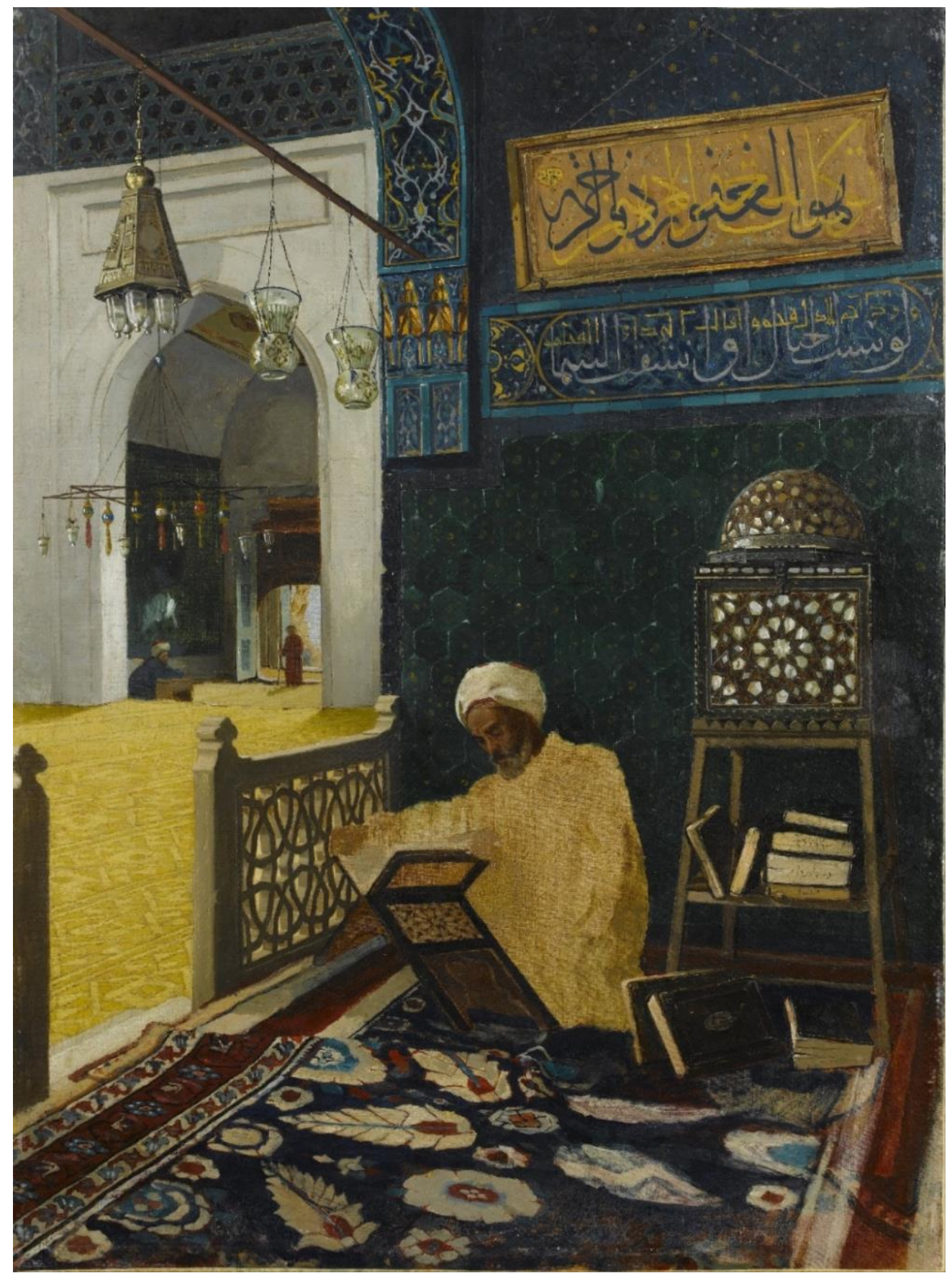

Şekil 2. Kuran Okuyan Adam (Kur'an Tilaveti). Yapım Yılı:1910. Tekniği: Tuval üzerine Yağllboya. Boyut:72,5 cm x $53 \mathrm{~cm}$. Bulunduğu Yer: Sabancı Müzesi İstanbul (URL-4).

"Kuran Okuyan Adam (Kur'an Tilaveti)" isimli tabloda (Şekil 2) Osman Hamdi Bey, kendisini Kur'an okurken resmetmiştir. Osman Hamdi Bey bu resimde bir tasarrufta bulunmuş olup, caminin girişini normalde bulunmadı̆̆ı bir konuma yerleştirmiştir. Girişte soldaki eyvan olduğu anlaşılan mekânda Kur'an tilavetini gerçekleştiren kişinin (kendisinin) hemen üzerinde bulunan iki belirgin yazı vardır. İlki ressamımızın diğer bazı tablolarında da kullanacağı sarı renkli "Müheymin olan Rabbimin mağfiretine tevekkül ettim. O çokça bağlşlayan merhamet sahibidir." mealindeki yazı, ikincisi ise bu eyvana has olan "Dağlar parça parça olsa, gökler yarllsa bile" anlamındaki yazıdır. Bu yazı Arapça olsa bile aslında Yeşil Camii’yi öven Farsça bir şiirin son cümlesidir (Kaptan, 2017). 


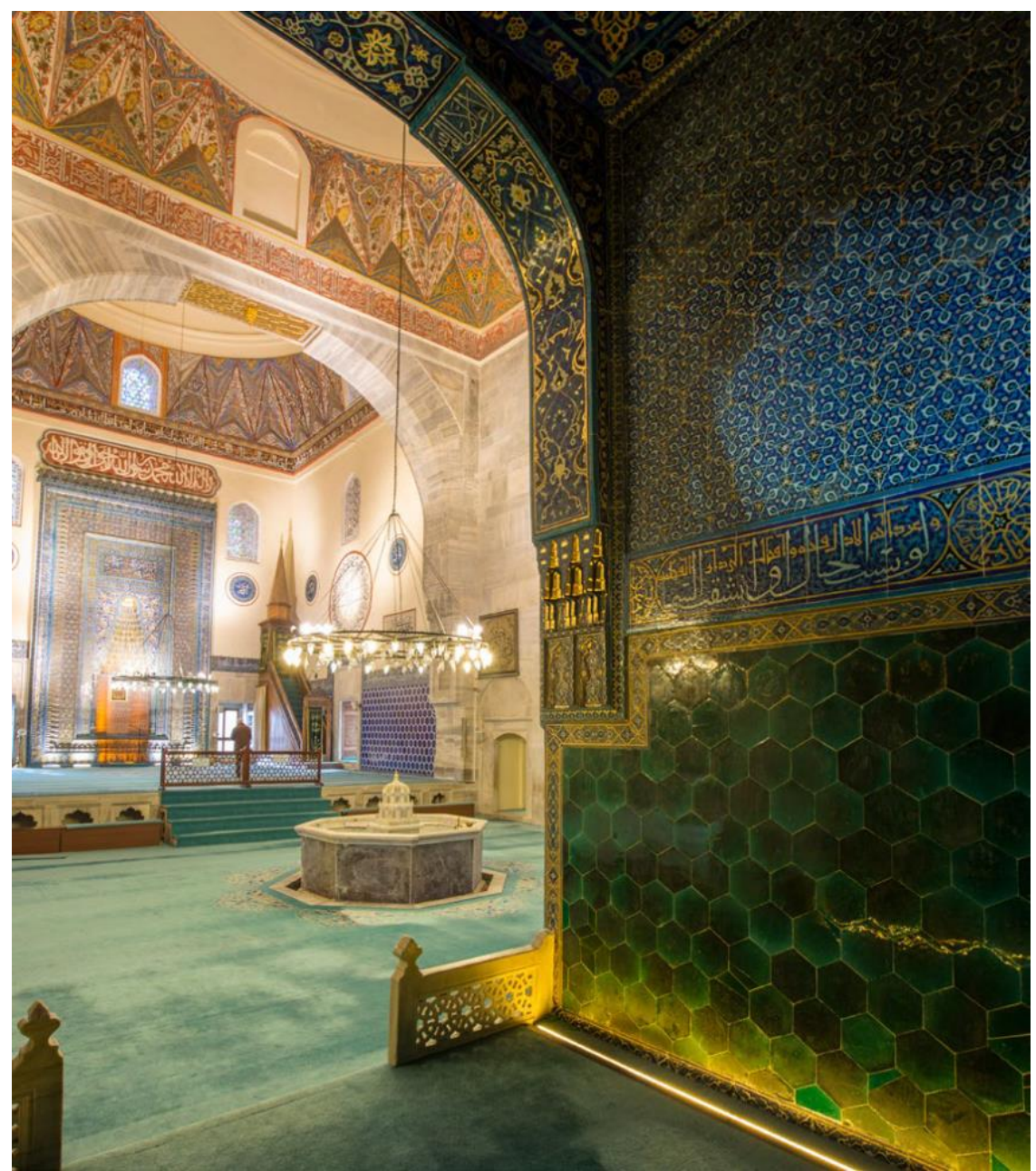

Fotoğraf 3. Bursa Yeşil Cami Girişinin Sol Tarafindaki Mahfili (Altepe, 2017).

Eserde geleneksel motifler net olarak dikkat çekmektedir. Bursa Yeşil Cami’de Kur'an okuyan bir figür resmedilirken Yeşil Cami çini özellikleri yansıtılmaya çalışılmış, figürün arkasındaki duvar kaplamasında yeşil altıgen formlu çiniler kullanılmıştır. Fotoğraf 3'te görüldüğü gibi caminin orijinal duvarında ise bu altıgen formlar üzerinde altın yaldız motifler yer almaktadır. Burada bulunan yazının üzerinde ise kufi ve sülüs yazılı kitabe resmedilmiştir. Ek olarak sol tarafta bulunan kemer altında koyu lacivert zemin üzerine sarı ve açı mavi renklerinde rumi motifler bezenirken turkuaz zemin üzerinde mukarnas çinilerde kullanılan renk sarıdır (Maltepe, 2019). 


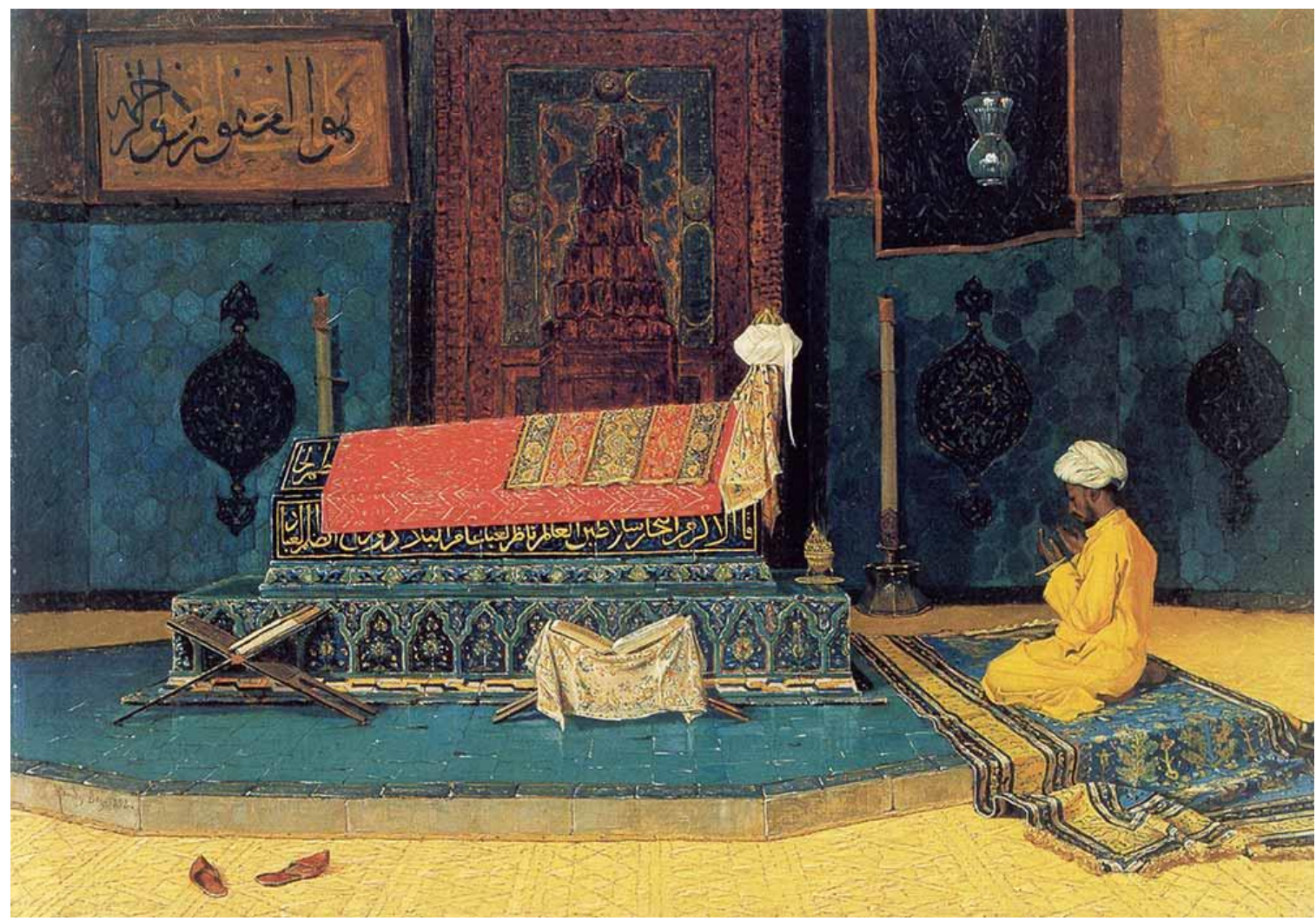

Şekil 3. Yeşil Türbe’de Dua. Yapım Yılı:1882. Tekniği: Tuval üzerine yă̆lıboya. Bulunduğu Yer: Kudret Türksan Koleksiyonu (Maltepe, 2019).

1882 de yapılan "Yeşil Türbe'de Dua” eserinde (Şekil 3), Yeşil Türbe'nin yine mekân olarak kullanıldığı görülmektedir. Detayları oldukça fazla görülen sanduka çinilerinde sandukanın üzerine oturtulduğu kaidenin en alt tarafinda sarı, turkuaz ve kobalt mavi renklerinde geometrik geçme motifler dikkat çekmektedir. Üstünde ise kısımlara ayrılmış rumi ve hatai motifli lacivert ve turkuaz formlu çiniler görülmekte olup, sandukanın kaidesi ise sarı turkuaz rumi motifleri ile bezenmiştir. Diğer resimlerden farklı olarak duvarları kaplayan yüzey çinileri turkuaz tek renkli altıgen formlu çinilerin ortalarında madalyon formlu tasarımlar yer almaktadır.

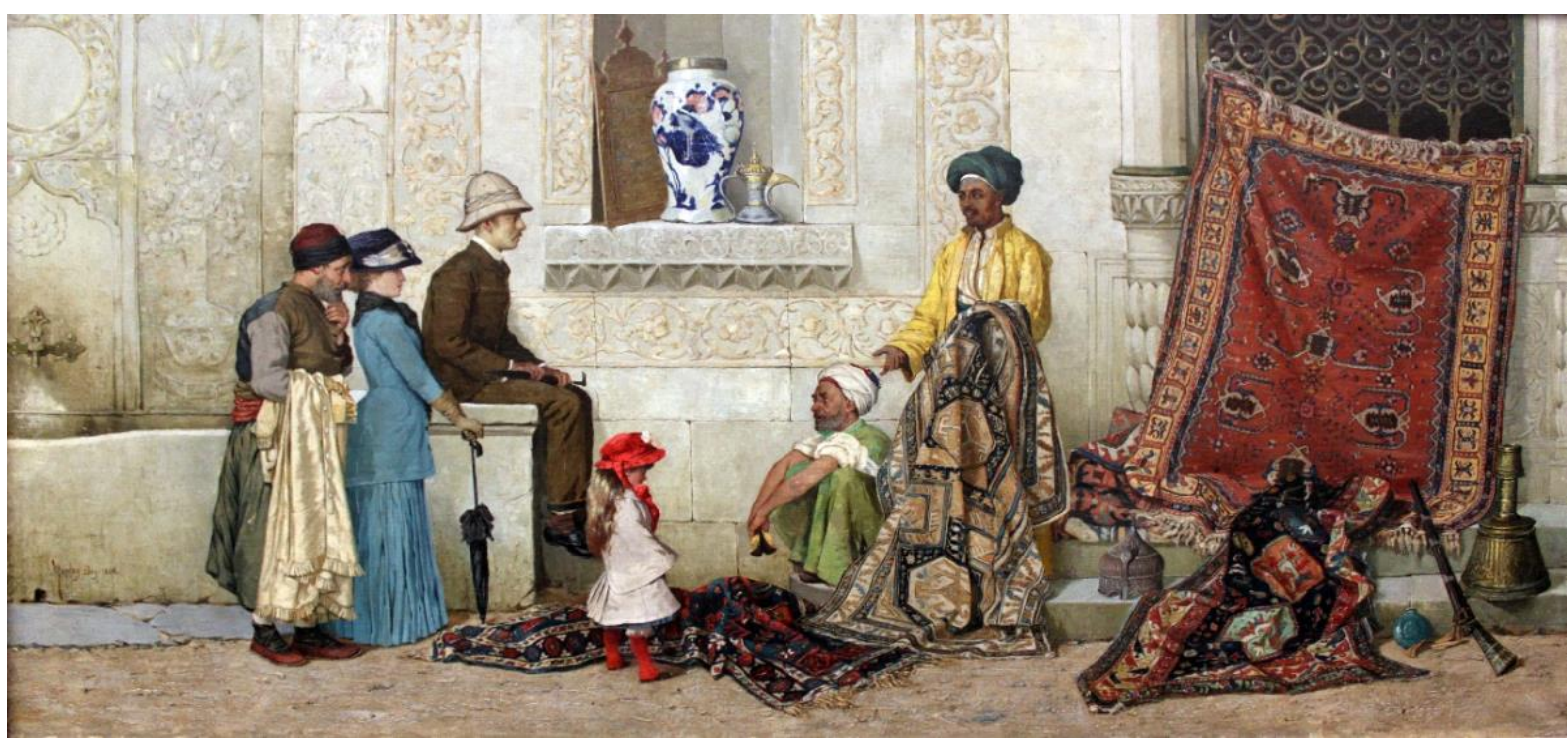

Şekil 4. Halı Satıcısı. Yapım Yılı:1888. Tekniği: Tuval üzerine yă̆lıboya. Bulunduğu Yer: Berlin Devlet Müzesi (URL-5) 
Osman Hamdi Bey’in, "Halı Satıcısı" adlı tablosunda (Şekil 4) Doğu Anadolu Bölgesi'ne ait olduğu tahmin edilen büyük hayvan motifli bir halı tasviri dikkat çekmektedir. Stilize hayvan motiflerinin yanı sıra yaprak, çiçek, gül gibi motifler kenar kısımlara yerleştirilmiştir. Bu halının hemen hemen aynı kompozisyonunda iki adet halı, Ankara Vakıf Eserleri Müzesinde yer almaktadır. Duvarda asılı olan halının XIX. yüzyıla ait bir Anadolu Yörük halısı, satıcının elinde tuttuğu halının ise XIX. yüzyıla ait bir Kafkas halısı olduğu söylenebilir. Sarı renkli zemin üzerine ise tek sıra bordür ve tekrar eden motifler hâlinde minik kareler içerisinde stilize kuş motifleri yer almakta, küçük üçgenlerden oluşturulmuş bir sıra zikzak ve son olarak mavi renkli iki ince bir bordür yer bulunmaktadır (Bayraktaroğlu, 2011).

\section{DEĞERLENDİRME VE SONUÇ}

Ressamlarımız Anadolu'nun binlerce yıllık kültürel mirasından ve yaşantısından izleri, bazı eserlerde gerçekçi bazı eserlerde izlenimci ya da soyut yorumlarla çalışmalarına aktarmışlardır. İlk portre ressamlarımız arasında gösterilen Osman Hamdi Bey de sadece manzara resimleri yapmamış; aynı zamanda çok sayıda figürün yer aldığı kompozisyonlar kurgulayarak, Türk kültürüne ait motifleri işlemiştir.

Avrupa'da aldığı resim eğitimi ile Osmanlıya geri dönüş yapan ve en nadide eserlerini, Osmanlı topraklarında veren Osman Hamdi Bey, farklı bölgelerde yapmış olduğu görevler sebebiyle tablolarında çok geniş bir perspektif kullanmış ve geniş bir tablo kataloğu oluşturmuştur. Ressam, Anadolu dışında yer alan mimari ve mimari elemanları da tablolarında kullanmıştır. Osman Hamdi Bey, tablolarında kullandığı bazı mimari eserleri yerinde inceleyip tuvaline işlerken bazı mimari eserleri ise fotoğraf yoluyla tablosunda kullanmıştır. Bir mimari yapıyı, birden fazla tablosunda kullandığı da olmuştur.

Çoğunlukla fotoğraflardan tek tek kopyaladığı özgün nesneleri kolaj tekniğiyle bir araya getiren Osman Hamdi, resimlerinde sahneleri ve onları oluşturan öğeleri foto-gerçekçi betimlemelere dayanarak kurgulamıştır. Çini, özellikle son dönemlerinde Osman Hamdi Bey'in yaptığ 1 resimlerde oldukça fazla kullandığı dekoratif bir unsurdur. Sanatçının resmettiği tablolarının bazılarında İznik çinilerinden örneklere rastlanırken, bazılarında ise binaların süslemelerinde hat örnekleriyle bezeli çinilere, çiçek bezemeli bordürlere yer verilmiştir. Genellikle kurguladığı ortamda mimari süslemelerin yanı sıra; İslami özelliklere sahip bir figür, renkli geleneksel bir elbise benzeri giysi ve başlık, yazmalar, şamdanlar, rahleler, halılar, lambalar gibi birkaç tane yöresel nesne bulunur. Resimlerinde çiniler, hat sanatı örneği kitabeler, oymalı ahşap kapılar, sivri kemerler gibi dekoratif malzemelerle donanmış, kısmen mimari bir ortamda özellikle renklerin uyumuna, kumaşların yumuşak parıltısına, sırlı çinilere rastlama mak mümkün değildir (Kuvvetli, 2018).

Sonuç olarak bu çalışmada; eserlerine geleneksel sanatları yansıtmış 19. yüzyıl oryantalist ressamları arasında yer alan fakat diğer oryantalist ressemlardan farklı olarak yansıttığ 1 kültürün bulunduğu topraklarda doğmuş, o kültürü almış, sanatıyla, mimarisiyle iç içe olmuş olan Osman Hamdi Bey'in dört eserini incelemeye çalıştık. Her ne kadar Paris’te eğitim alıp Batılı ressamlarla çalışsa da eserlerindeki detayları incelediğimizde geleneksel sanatların Doğu ve Batı tasavvurlarının, kimi zaman gerçekçi kimi zaman da izlenimci yorumları görülmektedir. Sanatçının eserlerinin birçoğunda gerek kurgu aşamasında mimari mekân kullanımı olarak gerekse mekân süslemeleri açısından Osmanlı mimari eserlerini ve bu eserlerdeki motifleri süsleme unsurlarını, bezemeleri büyük bir titizlikle işlemesi bakımından geleneksel sanatlarımızdan izler taşıdı̆̆ 1 açıktır. 


\section{KAYNAKLAR}

Altepe, R. (2017). Osman Hamdi Bey'in Tablolarında; Yeşil Cami Yazıları. Bursa'da Zaman, s. 18-23.

Aslanapa, O. (1989). Türk Sanatı El Kitabı. İstanbul: İnk1lap Kitabevi.

Aslanapa, O. (2000). Türk Sanatı. İstanbul: Remzi Kitabevi.

Bayraktaroğlu, S. (2011, Aralık). Osman Hamdi Bey'in Tablolarındaki Bazı Halı Tasvirleri Ve Bu Halılardaki Motifin İrdelenmesi. Vakıflar Dergisi, 171-185.

Bayramoğlu, M. (2013). 20. Yüzyıl Türk Resim Sanatında Geleneksel Türk Sanat Örneklerinin Etkisi. Kalem İsi Dergisi, 1(2), 1-40.

Cezar, M. (1971). Sanatta Batıya Açılış ve Osman Hamdi (1. Bask1). İstanbul: Türkiye İş Bankası Kültür Yayınları.

Çubukçu, P. D. (1987). Kültür Tarihimizde Sanatın Değeri. Ankara Üniversitesi Illahiyat Fakültesi Dergisi, 29(1), 135-144.

Derman, M. (2001). Osmanlı Hat Sanatı. İstanbul: Mas Matbaacılık.

Gündüz, F. (2007). Osman Hamdi Bey. TDV İslâm Ansiklopedisi (Cilt. 33, ss.468-469). TDV İslâm Araştırmaları Merkezi.

Harmankaya, H. (2015, Temmuz). Osmanlı Dönemi Oryantalist Resimlerde Görülen Kadın Figürleri Ve Giyim Özellikleri. Special Issue On The Proceedings Of The 4th Iscs Conference, 764-781. İlden, S. (2013). Geleneksel Sanatların Ötekileştirilmesi Sorunu. Akdeniz Sanat Dergisi, 6(12), 241-251.

Kaptan, Ö. (2017, Nisan). Osman Hamdi Bey'in Tablolarında; Yeşil Cami Yazıları. Bursa'da Zaman, S. 18-24.

Kaya, G. S. (2019). Sultan Abdülaziz Ve Döneminin Resim Sanatı. Milli Saraylar Sanat Tarih Mimarlı Dergisi, 77-101.

Kuvvetli, F. (2018). Görünenin Ötesinde Osman Hamdi Bey, İstanbul: Çağatay Anadol Kitap Yayınevi Ltd.

Maltepe, Z. B. (2019). 19. Yüzyılda Oryantalist Ressamların Eserlerinde Çini Sanatı. Sakarya: Sakarya Üniversitesi Sosyal Bilimler Enstitüsü.

MEGEP. (2009). Bitkisel Motif Çzimi. Ankara: Milli Eğitim Bakanlı̆̆ı.

MEGEP. (2011). Motif Çizim Temel Teknikleri. Ankara: Milli Eğitim Bakanlığı.

YERLİ, S. (2020). Osman Hamdi Bey'in Resimlerinde Tinsellik. International Journal of Interdisciplinary ad Intercultural Art, 5(11), 245-254.

URL-1:https://tr.m.wikipedia.org/wiki/Dosya:Ye\%C5\%9Fil_Cami_mihrab\%C4\%B1.jpg

(Erişim Tarihi: 15.09.2021).

URL-2:https://blog.peramuzesi.org.tr/wp-content/uploads/2013/04/SVIKV.RK_.0009.jpg

(Erişim Tarihi: 15.09.2021).

URL-3:https://upload.wikimedia.org/wikipedia/commons/1/1b/Bursa014.jpg (Erişim Tarihi: 16.09.2021).

URL4:https://tr.wikipedia.org/wiki/Kur\%27an_Til\%C3\%A2veti_(tablo)\#/media/Dosya:O sman_Hamdi_Bey_-_Kur\%E2\%80\%99an_Tilaveti_,Reciting_the_Quran_-

_Google_Art_Project.jpg (Erişim Tarihi: 20.09.2021)

URL5:https://tr.wikipedia.org/wiki/Hal\%C4\%B1_Sat\%C4\%B1c\%C4\%B1s\%C4\%B1\#/m edia/Dosya:1888_Bey_Persischer_Teppichh\%C3\%A4ndler_auf_der_Stra\%C3\%9Fe_anagoria.JP G (Erişim Tarihi: 20.09.2021) 


\section{EXTENDED ABSTRACT}

It is benefited from different art styles and expressions transferring Traditional Turkish Arts to next generation. It can be said that Turkish painting art has an important role. Osman Hamdi's painting who was the important artist of Turkish paintings art reflects the features of Turkish painting. In this study Osman Hamdi's painting has been viewed on Traditional Turkish Art parts such as designs, motives, colors and compositions.

In this article four painting that exhibits in different galleries, "İki Müzisyen Kız" , "Kur'an Okuyan Adam", "Yeşil Türbe'de Dua" and "Halı Satıcısı" are chozen as sample. Osman Hamdi Bey's these works were examined and evaluated in terms of motif, color and composition features of traditional Turkish arts.

The work named "İki Müzisyen K1z (Two Musician Girls)" (Photo 2) is one of Osman Hamdi Bey's most important works, and the prayer place in Bursa Yeşil Mosque is the place in the painting. In the introductory part of this section, there are two young girls playing the tambourine and tambourine, our traditional instruments. While the girl playing the tambourine is sitting, the girl playing the tambourine is standing. The standing girl is wearing a blue dress with gold patterns on a cream-colored background, and a baggy bag made of the same fabric. The seated girl has tied a golden yellow sash, and is wearing three skirts with gold stripes on blue. As we can see from this study, it is striking that women dressed in closed clothes in accordance with the dressing styles of the period. One of the most important features of this work is Hamdi Bey's approach to ornaments belonging to Ottoman culture.

In the painting named "Kur'an Okuyan Adam (Quran Recitation)" (Photo 4.), Osman Hamdi Bey portrayed himself while reading the Quran. In this painting, Osman Hamdi Bey has placed the entrance of the mosque in a location where it would not normally be. At the entrance, which is understood to be the iwan on the left, there are two distinctive inscriptions located just above the person who performed the Qur'an recitation. The first of these inscriptions is the yellow text that the artist used in some of his other paintings. The second of the articles is the last sentence of a Persian poem praising Bursa Yeşil Mosque. The traditional motifs clearly draw attention in the work. While a figure reciting the Qur'an was depicted in Bursa Green Mosque, Green Mosque tile features were tried to be reflected, and green hexagonal tiles were used on the wall covering behind the figure.

In the work named "Yeşil Türbe'de Dua (Prayer in the Green Tomb)", built in 1882, it is seen that the Green Tomb was again used as a place. Geometric interlaced motifs in yellow, turquoise and cobalt blue colors draw attention on the bottom side of the pedestal on which the sarcophagus is placed on the sarcophagus tiles, of which the tile details are abundant. On the top, dark blue and turquoise tiles with rumi and hatai motifs can be seen, and the pedestal of the sarcophagus is decorated with yellow turquoise rumi motifs. Unlike other paintings, there are medallion-shaped designs in the middle of the turquoise monochrome hexagonal tiles that cover the walls.

In Osman Hamdi Bey's painting ""Halı Satıc1s1 (The Carpet Seler)" (Picture 4), a depiction of a carpet with a large animal motif, which is thought to be Eastern Anatolian carpets, draws attention. In addition to stylized animal motifs, motifs such as leaves, flowers and roses are placed on the edges. Two carpets with almost the same composition of this carpet are in Ankara Foundation Works Museum. The carpet hanging on the wall XIX. An Anatolian Yörük carpet belonging to the XIX century, the carpet held by the seller is from the XIX. It can be said that it is a Caucasian carpet belonging to the 19 th century. 
In this research, 4 works of Osman Hamdi Bey, who was among the orientalist painters who reflected traditional arts in his works in the 19th century, were examined. Osman Hamdi Bey, who returned to the Ottoman Empire with the painting education he received in Europe and gave his most precious works in the Ottoman lands, used a wide perspective in his paintings and created a wide catalogue, due to the duties he had done in different regions. The painter also used architectural and architectural elements outside of Anatolia in his paintings. While Osman Hamdi Bey examined some of the architectural works he used in his paintings on-site and embroidered them on his canvas, he used some architectural works in his painting through photography. He used an architectural structure in more than one of his paintings.

Osman Hamdi, who mostly brings together the original objects that he copied one by one from the photographs with the collage technique, fictionalized the scenes and the elements that make them up in his paintings based on photo-realistic descriptions. Tile is a decorative element that Osman Hamdi Bey uses a lot in his paintings, especially in his last period. In some of the paintings painted by the artist, examples of Iznik tiles are found, while in some of the decorations of the buildings, tiles decorated with calligraphy samples and borders with flower decorations are included. In addition to the architectural decorations in the environment he usually constructs; There are several local objects such as a figure with Islamic features, a colorful traditional dress-like dress and headdress, writings, candlesticks, lecterns, carpets, lamps. It is impossible not to come across especially the harmony of colors, soft glow of fabrics, glazed tiles in a partially architectural environment equipped with decorative materials such as tiles, calligraphy inscriptions, carved wooden doors, pointed arches in his paintings.

Although Osman Hamdi Bey studied in Paris and worked with Western painters, sometimes realistic and sometimes impressionist interpretations of traditional arts are seen in his works. It is clear that many of the artist's works bear traces of our traditional arts, both in terms of the use of architectural space during the editing phase and in terms of space decorations, in terms of processing Ottoman architectural works and the motifs, ornamental elements and decorations in these works with great care. 